\title{
Loss of LR11/SORLA Enhances Early Pathology in a Mouse Model of Amyloidosis: Evidence for a Proximal Role in Alzheimer's Disease
}

\author{
Sara E. Dodson, ${ }^{1}$ Olav M. Andersen, ${ }^{4}$ Vinit Karmali, ${ }^{1}$ Jason J. Fritz, ${ }^{1,2}$ Dongmei Cheng, ${ }^{1,3}$ Junmin Peng, ${ }^{1,3}$ \\ Allan I. Levey, ${ }^{1,2}$ Thomas E. Willnow, ${ }^{5}$ and James J. Lah ${ }^{1,2}$ \\ ${ }^{1}$ Center for Neurodegenerative Disease, Departments of ${ }^{2}$ Neurology and ${ }^{3}$ Human Genetics, Emory University, Atlanta, Georgia 30322, ${ }^{4}$ The MIND Center, \\ Department of Medical Biochemistry, Aarhus University, 8000 Aarhus, Denmark, and ${ }^{5}$ Max-Delbrueck-Center for Molecular Medicine, D-13125 Berlin, \\ Germany
}

\begin{abstract}
Alzheimer's disease $(\mathrm{AD})$ is the most prevalent form of dementia, resulting in progressive neuronal death and debilitating damage to brain loci that mediate memory and higher cognitive function. While pathogenic genetic mutations have been implicated in $\sim 2 \%$ of $\mathrm{AD}$ cases, the proximal events that underlie the common, sporadic form of the disease are incompletely understood. Converging lines of evidence from human neuropathology, basic biology, and genetics have implicated loss of the multifunctional receptor LR11 (also known as SORLA and SORL1) in AD pathogenesis. Cell-based studies suggest that LR11 reduces the formation of $\beta$-amyloid (A $\beta$ ), the molecule believed to be a primary toxic species in AD. Recently, mutant mice deficient in LR11 were shown to upregulate murine A $\beta$ in mouse brain. In the current study, LR11-deficient mice were crossed with transgenic mice expressing autosomal-dominant human AD genes, presenilin-1 (PS1 $\Delta$ E9) and amyloid precursor protein (APPswe). Here, we show that LR11 deficiency in this AD mouse model significantly increases $\mathrm{A} \beta$ levels and exacerbates early amyloid pathology in brain, causing a forward shift in disease onset that is LR11 gene dose-dependent. Loss of LR11 increases the processing of the APP holo-molecule into $\alpha$-, $\beta$-, and $\gamma$-secretase derived metabolites. We propose that LR11 regulates APP processing and A $\beta$ accumulation in vivo and is of proximal importance to the cascade of pathological amyloidosis. The results of the current study support the hypothesis that control of LR11 expression may exert critical effects on Alzheimer's disease susceptibility in humans.
\end{abstract}

Key words: LR11; SORLA; SORL1; transgenic mouse; $\beta$-amyloid; Alzheimer's disease; APOE

\section{Introduction}

Alzheimer's disease (AD) is the most prevalent form of dementia, affecting nearly half of elderly persons over the age of 85 , and over 5 million individuals in the United States alone. Understanding of the molecular underpinnings of the disease process has greatly advanced in the last 20-30 years; however, the exact molecular events that trigger the disease cascade remain elusive. Recently, converging lines of evidence from human neuropathology, basic biology, and genetics have implicated LR11 (also known as SORLA and SORL1) in AD pathogenesis. LR11 is a type- 1 transmembrane protein belonging to both the APOE-binding lowdensity lipoprotein receptor family and the vacuolar protein sorting 10 protein (VPS10p) family of intracellular sorting receptors

\footnotetext{
Received Sept. 13, 2008; accepted 0ct. 15, 2008.

This work was supported by National Institutes of Health Grants AG05136 (J.J.L.) and F31 NS055881 (S.E.D.), and by the Deutsche Forschungsgemeinschaft (T.E.W.). We gratefully acknowledge Stephanie Carter for excellent technical assistance and Joanne Wuu for providing expert statistical advice.

Correspondence should be addressed to either of the following: James J. Lah, Center for Neurodegenerative Disease, 615 Michael Street, Suite 505 S, Atlanta, GA 30322, E-mail: jlah@emory.edu; or Thomas E. Willnow, MaxDelbrueck-Center for Molecular Medicine, R. Roessle Strasse 10, D-13125 Berlin, Germany, E-mail: willnow@mdc-berlin.de.

DOI:10.1523/JNEUROSCI.4582-08.2008

Copyright $\odot 2008$ Society for Neuroscience $\quad$ 0270-6474/08/2812877-10\$15.00/0
}

(Yamazaki et al., 1997; Jacobsen et al., 2001; Herz and Bock, 2002). We first established the connection between AD and LR11 with the observation that LR11 protein is consistently reduced in vulnerable neurons in AD brain (Scherzer et al., 2004). Recently, variants of the LR11 gene (SORL1) were shown to correlate with risk of sporadic $\mathrm{AD}$ in several populations, providing direct genetic evidence for a proximal role of LR11 in AD (Lee et al., 2007b; Meng et al., 2007; Rogaeva et al., 2007; Tan et al., 2007).

$\beta$-amyloid ( $\mathrm{A} \beta$ ) peptide is the major component of the hallmark senile plaques found in $\mathrm{AD}$ (Glenner and Wong, 1984). A $\beta$ is toxic to neurons, and the aggregation of $\mathrm{A} \beta$ is believed to culminate in neurodegeneration and clinical disease. Over the past two decades, the molecules that control the processing of the amyloid precursor protein (APP) into $A \beta$ have been intensely investigated (Weidemann et al., 1989; Gandy and Petanceska, 2000; Ehehalt et al., 2003; Ling et al., 2003; Gralle and Ferreira, 2007). Recent studies have established that LR11 physically interacts with APP and the $\beta$-site APP cleaving enzyme (BACE- 1 ) and that overexpression of LR11 reduces $A \beta$ production in cultured cells (Andersen et al., 2005, 2006; Offe et al., 2006; Spoelgen et al., 2006). Moreover, mice deficient for LR11 exhibit increased levels of murine $\mathrm{A} \beta$ (Andersen et al., 2005).

In the current study, we explore whether LR11 is capable of 
influencing Alzheimer's disease-related pathology in vivo. Mice carrying mutant PSEN1 with Exon 9 deletion (PS1 $\triangle \mathrm{E} 9)$ and the K595M/N596L human "Swedish" mutant APP (APPswe) were crossed with mice expressing reduced levels of LR11 $\left(\operatorname{Lr} 11^{\Delta E x 4}\right)$. LR11 deficiency results in early increases in both $A \beta 40$ and $A \beta 42$ along with accelerated amyloid deposition in brain. The magnitude of these changes correlates directly with LR11 levels. In cortical tissue and primary neuronal cultures, LR11-deficiency produces significant changes in levels of the secreted metabolites of APP (APPs) and APP C-terminal fragments (CTFs), suggesting that loss of LR11 drives increased processing of the APP holoprotein and increased generation of the $\mathrm{A} \beta$ peptide. Recent work suggests that LR11 expression may play a protective role against $\mathrm{AD}$, and our current study provides compelling evidence that LR11 loss directly contributes to early pathogenic events in vivo through the regulation of cellular APP processing events.

\section{Materials and Methods}

Mouse background and breeding. LR11 deficient mice were engineered by targeted gene deletion of the $5^{\prime}$ region of Sorll Exon 4 in 129 SvJ/Bl6 mice (Andersen et al., 2005). In the course of the present study, these LR11 deficient mice were shown to make an unexpected splice variant of LR11 that is expressed at very low levels in brain. We now designate these mice as $\operatorname{Lr} 11$ exon 4 deletion mutants $\left(\operatorname{Lr} 11^{\Delta E x 4}\right)$, but given their very low expression levels and lack of wild-type LR11, we will continue to refer to these mice as $\operatorname{Lr}_{11}{ }^{-1-}$. Homozygous $\operatorname{Lr} 11^{\Delta E x 4}\left(\operatorname{Lr} 11^{-1-}\right)$ mice were crossed with heterozygous double transgenic mice carrying the human PS1 with exon 9 deletion $\left(P S 1^{\Delta E 9}\right)$ mutation and the K595M/N596L "Swedish" APP $\left(A P P^{S w e}\right)$ mutation, which originally integrated at the same locus on Bl6/C3 mouse background (Jackson Laboratories) (Borchelt et al., 1996, 1997; Jankowsky et al., 2004). PS1/APP transgenic F1 progeny from the first cross were bred to wild-type LR11 hemizygous mice, and $\mathrm{LrI1}^{+/+}, \mathrm{Lrll}^{+/-}$, and $\mathrm{LrI1}^{-/-}$littermates carrying $P S 1^{\Delta E 9}$ / $A P P^{S w e}$ were used for analysis. In total, 48 mice were analyzed in this study across 4 different age groups: 3 months $\left(\operatorname{Lr} 11^{+/+} n=6 ; \operatorname{Lr}_{11}{ }^{-1-}\right.$ $n=4), 4.5$ months $\left(\operatorname{Lr} 11^{+/+} n=5 ;{\operatorname{Lr} 11^{+/-}}_{n}=4 ;{\operatorname{Lr} 11^{-1-}} n=5\right), 6$ months $\left(\operatorname{Lr} 11^{+/+} n=9 ; \operatorname{Lr}_{1} 1^{-/-} n=5\right)$, and 12 months $\left(\operatorname{Lr} 11^{+/+} n=\right.$ 6; $\left.\operatorname{Lrl1}^{-1-} n=4\right)$. Refer to supplemental Table 1, available at www. jneurosci.org as supplemental material, for the gender of animals in each experimental group.

Characterization of LR11 message expression. Total RNA was isolated from $\mathrm{LrI1}^{+/+}, \mathrm{LrI1}^{+/-}$, and $\mathrm{Lr} 11^{-1-}$ tissues using the TRIzol reagent (Sigma) according to the manufacturer's recommended protocol. Isolated RNA was treated with Turbo DNase Free (Ambion) to remove contaminating genomic DNA. Two-step reverse transcription-PCR (RTPCR) was performed from $1 \mu \mathrm{g}$ DNase-free total RNA using the SuperScript First-Strand Synthesis System (Invitrogen) with an oligo(dT) primer, followed by PCR using hi-fidelity AccuPrime Pfx DNA Polymerase (Invitrogen) with $\operatorname{Lr} 11$ exon-specific primer sets, each designed to amplify $\sim 1 \mathrm{~kb}$ regions from the full-length $\operatorname{Lr} 11$ transcript (GenBank Accession\# NM_011436). Sequences for the PCR primers used were: exon 1 sense (5'-ATG GCG ACA CGG AGC AGC AGG-3'), exon 3 sense ( $5^{\prime}$-CTT TGG CGT GGG CAA CAA CAG CG-3'), exon 4 sense ( $5^{\prime}$-TAC ATC TTT GTG GAT GCT TAC GCC CAA TAC C- $3^{\prime}$ ), exon 4 antisense (5' -CCT GTC AAA GCC CAA GAG GAG GTT GGA GG-3'), exon 5 antisense $\left(5^{\prime}\right.$-CGT GTT CCT GAA TCA TGA TCC AGG TCT GGC C-3'), exon 7 antisense (5'-GGA TGC TTT GTG ACA AAC TGG GCT GC-3'), exon 8 sense (5' $5^{\prime}$ CTG ATG CCG AGG ACC AGG-3'), exon 15 antisense (5'-CAC AGG ACA AGG CAC AGG AGG GC-3'), exon 16 sense (5'-CTA TCG GAA GAT TTC TGG GGA TAC GTG C-3'), exon 22 antisense ( $5^{\prime}$-CCA GAG GGG AGG ACA CTG CTG G-3'), exon 23 sense ( $5^{\prime}$-GCA ACC AGT ACC GCT GCA GCA ACG-3'), exon 31 antisense (5'-GGG CAG GCC TCC TCA TCA GAG C-3'), exon 32 sense (5' -CAA ACT CCA CTG CCG CCT CCA C-3'), exon 40 antisense (5' ${ }^{\prime}$-CCC TCC GCG GAA GCT CAG G-3'), exon 41 sense ( $5^{\prime}$-GCC TGG GCC AAG ACA GAC TTG GG-3'), exon 48 antisense ( $5^{\prime}$-CAT CGT CCT CTC CTA GGT CAT CCC CTG AGG-3'). For each primer set, thermocycling was performed using the following protocol: (1) $94^{\circ} \mathrm{C}$ for $2 \mathrm{~min}$; (2) 35 cycles of $94^{\circ} \mathrm{C}$ for $30 \mathrm{~s}, 57.5^{\circ} \mathrm{C}$ for $30 \mathrm{~s}$, and $68^{\circ} \mathrm{C}$ for $2 \frac{1}{2} \mathrm{~min}$; and $(3) 68^{\circ} \mathrm{C}$ for $10 \mathrm{~min}$. The amplified RT-PCR products were separated by electrophoresis on $1 \%$ agarose gels, stained with ethidium bromide, and visualized using the Flurochem 8800 gel documentation system (Alpha Innotech Corporation). Following agarose gel electrophoresis, RT-PCR products were excised and the DNA recovered using the Qiaquick Gel Extraction Kit (Qiagen). Purified RT-PCR products were then sequenced at Lark Technologies using both the sense and antisense PCR primers. DNA sequencing results were aligned with the wild-type mouse Lr11 mRNA sequence (NM_011436) and analyzed using the AlignX function of the Vector NTI software suite (Invitrogen).

Identification of LR11 protein by mass spectrometry. LR11 from mouse brain was enriched by immunoprecipitation, separated by SDS PAGE and stained with Coomassie Blue G-250. The LR11-containing band was excised from the gel and digested by trypsin. The digested peptides were extracted from the gel piece and analyzed by liquid chromatography coupled with tandem mass spectrometry using an LTQ-Orbitrap hybrid mass spectrometer (Thermo Finnigan) (Peng and Gygi, 2001). The collected MS/MS spectra were searched against mouse database, and filtered by matching scores and mass accuracy $(15 \mathrm{ppm})$ to reduce the false discovery rate to near zero using the target-decoy strategy (Peng et al., 2003). Namely, the filtering cutoffs were adjusted until all peptide matches from the decoy database were removed. Finally, the peptide matches of LR11 were manually verified with assigned product ions.

Tissue collection. Animals were killed and brains hemisected. One hemisphere was dissected and snap frozen on liquid nitrogen for use in biochemical measures. The other hemisphere was immersion fixed in $4 \%$ paraformaldehyde for $2 \mathrm{~h}$ at $4^{\circ} \mathrm{C}$ then transferred to $30 \%$ sucrose overnight for preparation for immunohistochemistry.

Tissue preparation for biochemical analysis. Cortical tissue from one hemibrain of each mouse was lysed in a Konte's tissue douncer (Pierce) in PBS with protease inhibitor mixture at $10 \%$ weight by volume (100 $\mathrm{mg} / \mathrm{ml}$ ) and further prepared for either ELISA analysis (see below) or Western blotting. For Western blot analysis of APP metabolites, membrane and soluble fractions were isolated by differential centrifugation at $4^{\circ} \mathrm{C}$. Briefly, cortical homogenates were first subjected to a $1000 \times \mathrm{g}$ spin to remove nuclei and debris (P1). The supernatant (S1) was spun at $10,000 \times g$ for 20 min to pellet larger organelles and membrane proteins (P2), and the resulting supernatant (S2) was further spun at 100,000 $\times g$ to enrich for soluble proteins (S3). The P2 fraction was rinsed with a high-salt solution ( $500 \mathrm{~mm} \mathrm{NaCl}$ ) to remove membrane-associated proteins, and further spun at $10,000 \times g$ for 20 min to pellet membrane proteins $\left(\mathrm{P} 2^{\prime}\right)$. Finally, the washed membrane fractions were lysed in detergent buffer (50 mm Tris base, $150 \mathrm{~mm} \mathrm{NaCl}, 0.5 \%$ NP-40, $0.5 \%$ deoxycholate) and released into the supernatant following a 15,000 $\times g$ spin for $5 \mathrm{~min}$. The soluble and membrane fractions were further prepared for Western blot analysis described below.

Immunoblotting. Immunoblotting was performed according to standard procedures. Briefly, cortical tissue fractions were solubilized in Laemmli sample buffer, separated on SDS-polyacrylamide gels and transferred electrophoretically to PVDF membranes (Immobilon-P; Millipore). Blots were blocked for $1 \mathrm{~h}$ at room temperature using $1 \times$ Blocking Buffer (USB Corporation), probed with primary antibodies in TBS with $0.1 \%$ Tween 20 overnight at $4^{\circ} \mathrm{C}$ and with fluorophoreconjugated donkey anti-rabbit (Rockland) and donkey anti-mouse (Invitrogen) secondary antibodies at room temperature for $1 \mathrm{~h}$. Images were captured and band intensities quantified using an Odyssey Image Station (LiCor Biosciences).

Primary antibodies. LR11 antibodies used in this study include: mouse anti-LR11 at 1:200 [VPS10p domain epitope; used for immunoblotting, kindly provided by Dr. H. Bujo (Graduate School of Medicine, Chiba University, Chiba, Japan) (Hirayama et al., 2000)], rabbit anti-LR11 C-terminal domain at 1:2000 [3850.6; used for immunoblotting and immunohistochemistry, kindly provided by Dr. C. Schaller (Zentrum fuer Molekulare Neurobiologie, Universitaet Hamburg, Hamburg, Germany) (Hampe et al., 2000)]. Antibody preadsorption to compete out specific LR11 primary antibody binding for both immunoblotting and immunohistochemistry was performed using rabbit anti-LR11 CT 
(3850.6) at 1:2000 with $1 \mu \mathrm{g} / \mathrm{ml}$ free LR11 C-terminal peptide for $30 \mathrm{~min}$ at RT. Antibodies used in Western blot analysis of APP metabolites include: $6 \mathrm{E} 10$ at 1:1000 [mouse monoclonal to human APP sequence within the A $\beta$ domain between amino acids 1-16 (Invitrogen)], C8 at 1:5000 [rabbit polyclonal to C-terminal domain of APP, kindly provided by Dr. Dennis Selko (Harvard Medical School, Boston, MA), and 192wt and 192swe at 1:2000 [rabbit polyclonals to $\beta$-secretase cleaved fragment of wild-type (wt) or swedish (swe) mutant APPs, kindly provided by Dr. Peter Seubert at Elan Pharmaceuticals, Dublin, Ireland]. Amyloid plaques were immunostained using rabbit anti-A $\beta 42$ (Biosource-Invitrogen).

Histochemical plaque evaluation. Sagittal sections $(50 \mu \mathrm{m})$ were cut from immersion fixed hemispheres using a freezing microtome and collected into $0.1 \mathrm{M}$ phosphate buffer. Sections were either immunostained using an $\mathrm{A} \beta 42$ specific antibody (Biosource) or stained with $1 \%$ thioflavine-S solution to visualize cored amyloid plaques. For A $\beta 42 \mathrm{im}$ munohistochemistry, immunoperoxidase staining methods on free floating sections were performed as previously described (Dodson et al., 2006). Briefly, samples were incubated in affinity-purified rabbit polyclonal antibody against $\mathrm{A} \beta 42$ overnight at $4^{\circ} \mathrm{C}$, followed by a biotinylated goat anti-rabbit secondary antibody (Vector Laboratories) for $1 \mathrm{~h}$ at RT. Sections were then incubated in avidin-biotinylated horseradish peroxidase complex (Vector Laboratories) and immunoreactivity was visualized with 3,3'-diaminobenzidine tetrahydrochloride. For visualization of cored plaques, separate sections were mounted and dried onto superfrost slides. Slides were rehydrated for $1 \mathrm{~min}$ in $\mathrm{dH}_{2} \mathrm{O}$ and incubated in $1 \%$ thioflavine-S solution for $10 \mathrm{~min}$ at RT, then rinsed in 2 changes of $80 \%$ ethanol and additionally rinsed two times in $\mathrm{dH}_{2} \mathrm{O}$.

Plaque quantitation. Images of sagittal brain sections were captured using an Olympus BX51 microscope and Olympus software. Plaque densities were determined in blinded manner by manual plaque count of thioflavine-S staining or surface area of $\mathrm{A} \beta 42$ immunostaining using MetaMorph Imaging software (Molecular Devices). Plaque quantitation is represented as an average surface area or mean number of plaques per tissue section as determined from 4 tissue sections evenly distributed across $\sim 1 \mathrm{~mm}$ tissue thickness, medial to lateral (approximately $\mathrm{L} 2.0-\mathrm{L} 3.0)$.

Sequential amyloid extraction and sandwich ELISA. SDS was added to total cortical homogenates (100 mg wet weight $/ \mathrm{ml})$ at $2 \%$ final concentration and tissue samples were sonicated (30 s at level 7; Branson Sonifier 250, Krackeler Scientific) and centrifuged at $4^{\circ} \mathrm{C}$ for $1 \mathrm{~h}$ at $100,000 \times$ $g$ (Optima TLX Ultracentrifuge; Beckman Coulter). Supernatant was collected (SDS-soluble fraction) and the pellet was resuspended in equal volume $70 \%$ formic acid in water and sonicated again as described above. Formic acid fractions were neutralized by 1:20 dilution in $1.0 \mathrm{M}$ Tris base, $\mathrm{pH}$ 10.8. SDS fractions were diluted at least 1:40 and neutralized formic acid fractions diluted at least 1:50 in ELISA diluent buffer $(50 \mathrm{~mm}$ Tris base, $150 \mathrm{~mm} \mathrm{NaCl}, 0.5 \% \mathrm{NP}-40,0.5 \%$ deoxycholate, $0.1 \mathrm{mg} / \mathrm{ml}$ phenylmethylsulfonyl fluoride, protease inhibitor mixture, $\mathrm{pH}$ 7.4). Fractions were stored at $-80^{\circ} \mathrm{C}$ until ELISA analysis and were not subjected to more than one freeze-thaw cycle. Sandwich ELISAs specific for fulllength $A \beta 40$ and $A \beta 42$ amyloid species (Genetics Company) were used to measure $A \beta$ levels according to manufacturer's instructions. Plates were read at $450 \mathrm{~nm}$ on a Spectra Max Plus plate reader (Molecular Devices).

Preparation of primary cortical neurons for analysis of APP metabolism. Primary cultures were prepared from 3 matched sets of Lr11-/- and Lr11+/+ dams (not crossed to the PS1/APP mice) on embryonic day 18. Briefly, cortical material was dissected from mouse embryos and trypsinized. Cell viability was evaluated by trypan blue exclusion. Cortical cells were plated at a density of $80,000 \mathrm{cells} / \mathrm{cm}^{2}$ in $60 \mathrm{~mm}$ tissueculture dishes coated with $250 \mu \mathrm{g} / \mathrm{ml}$ poly-L-lysine. Cells were maintained in neuronal medium (Neurobasal medium (Invitrogen) containing 5\% B-27 supplement, 1\% penicillin/streptomycin, $1 \%$ L-glutamine, and $5 \mu \mathrm{M}$ the mitotic inhibitor aramycin-C). On day 3 postplating, cells were infected with wild-type human APP695lentivirus with a multiplicity of infection $\sim 1$ and allowed to incubate for $72 \mathrm{~h}$. On day 6 postplating, the viral media was removed and $1.5 \mathrm{ml}$ of fresh neuronal media was added and allowed to condition for $16 \mathrm{~h}$. On day 7 , conditioned media and cells were harvested and prepared for biochemical analysis.

Data analysis and statistics. Given the logarithmic increases in $\mathrm{A} \beta$ levels with advanced age, raw measures were transformed for statistical analysis and analyzed with nonparametric tests, when possible. To normalize ELISA measurements of $A \beta$, data were first transformed by taking the natural log of raw values, then standardized by calculating the z-score (individual value - group mean/group SD) within each measure (i.e., SDS-soluble fraction of $A \beta 40$, formic acid soluble fraction of $A \beta 42$, etc.). For combined values (i.e., total soluble $\mathrm{A} \beta$, total $\mathrm{A} \beta 40$, etc.), individual measure z-scores were averaged together. To detect LR11 genotype effects with age in the PS1/APP mice, a two-way ANOVA was performed on individual z-scores, followed by pairwise Mann-Whitney nonparametric $t$ tests to compare $A \beta$ measures within each age group. For quantitative plaque density measurements, raw values were transformed by taking the natural log and analyzed using a two-way ANOVA, KruskalWallis one-way ANOVA followed by Dunn's multiple comparison test, or Mann-Whitney nonparametric $t$ test. Western blotting analysis of APP and APP metabolites measured from primary cortical cultures and tissue preparations were analyzed using Student's $t$ test. All statistical comparisons were analyzed using GraphPad Prism (GraphPad Software).

\section{Results}

Lr11 ${ }^{-1-}$ mice were engineered by homologous recombination resulting in deletion of the $5^{\prime}$ region of Exon 4 within the $\operatorname{Lr} 11$ genomic sequence (Andersen et al., 2005). Previously, analysis using brain membrane preparations indicated absence of the receptor in mice homozygous for the gene deletion (Andersen et al., 2005; Ma et al., 2007). However, experimental results in the current study using a different set of anti-LR11 antisera suggested low levels of expression of a truncated receptor from the targeted gene locus. Therefore, experiments were performed to evaluate the possible existence of a truncated $\operatorname{Lr} 11$ mRNA and LR11 protein species in brain lysates of LR11 deficient animals.

Lr11 mRNA expression in $\mathrm{LrI1}^{-/-}$animals was determined by RT-PCR. Purified RNA samples from LR11 wild-type $\left(\mathrm{Lr} 11^{+/}\right.$ + ), LR11 deficient $\left(\mathrm{Lr}_{1} 1^{-/-}\right)$, and heterozygous $\left(\mathrm{Lr} 11^{+/-}\right)$mice were subjected to reverse transcription-PCR. Six primer pairs amplifying $\sim 1 \mathrm{~kb}$ regions of exons $1-7,8-15,16-22,23-31$, $32-40$, and $41-48$ were used to examine the integrity of the $\sim 6$ kb full-length LR11 message. Lr11 RT-PCR products were detected in both $\mathrm{Lr} 11^{-/-}$and $\mathrm{Lr} 11^{+/+}$samples using all primer pairs (data not shown). The size of Lr11 RT-PCR products detected in $\mathrm{LrI1}^{-/-}$samples was identical to that of $\mathrm{Lr} 11^{+/+}$samples with the exception of the region amplified by primers directed from exon 1 (sense) to exon 7 (antisense). While the RTPCR product generated from $L r 11^{+/+}$mice migrated on the gel at the predicted size of $1 \mathrm{~kb}$, the $L r 11^{-/-}$fragment was noticeably smaller ( $\sim 850 \mathrm{~kb}$ ) (data not shown). Given that the homologous recombination strategy used to engineer these mice targeted a region within exon 4 , we hypothesized that the size difference observed in RT-PCR products generated from the exon 1-7 primer set was due to partial or complete deletion of exon 4 . Amplification of Lr11 cDNA between exons 3 and 5 shows that Lr11 ${ }^{-1-}$ mice contain a RT-PCR product $\sim 160$ base-pairs smaller than that of wild-type (Fig. $1 A$ ). As expected, $L r 11^{+/-}$ mice make both the longer $(\sim 300 \mathrm{bp})$ and shorter $(\sim 140 \mathrm{bp})$ RT-PCR products. Attempts to amplify cDNA using primer sequences directed to the $5^{\prime}$ and $3^{\prime}$ ends of exon 4 failed to yield a detectable RT-PCR product from $\mathrm{Lr}_{1}{ }^{-1-}$ samples, while this band was observed at the predicted size $(\sim 160 \mathrm{bp})$ in $\mathrm{Lr} 11^{+/+}$ and $\mathrm{Lr} 11^{+/-}$samples (Fig. $1 A$ ).

To further characterize this smaller Lr11 transcript, RT-PCR was performed using a primer set to amplify the cDNA region 


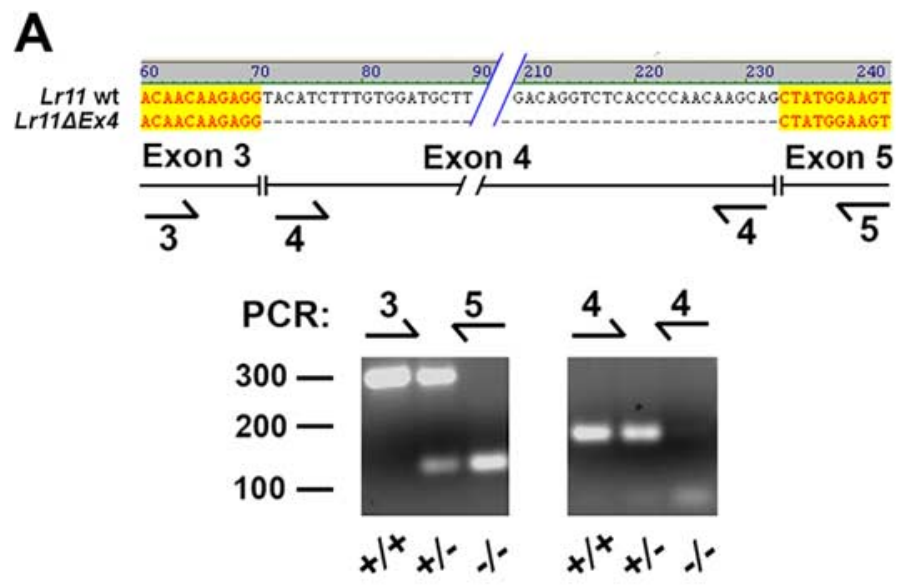

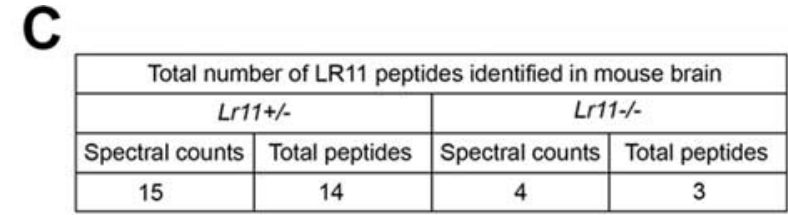

LR11 Peptides Identified in Lr11-/- brain:

$$
\begin{aligned}
& \text {... } \mathrm{RE}^{288} \text { NQEVILEEVR }{ }^{298} \mathrm{D} \text {.. } \\
& \text {... KE }{ }^{498} \text { SAPGLIIATGSVGK }{ }^{512} \mathrm{~N} \text {.. } \\
& \text {.... KI }{ }^{2020} \text { TTVSLSAPDALK }{ }^{2032} \text { I... }
\end{aligned}
$$

\section{Identification of unique LR11 peptide in Lr11-/- brain: ESAPGLIIATGSVGK}

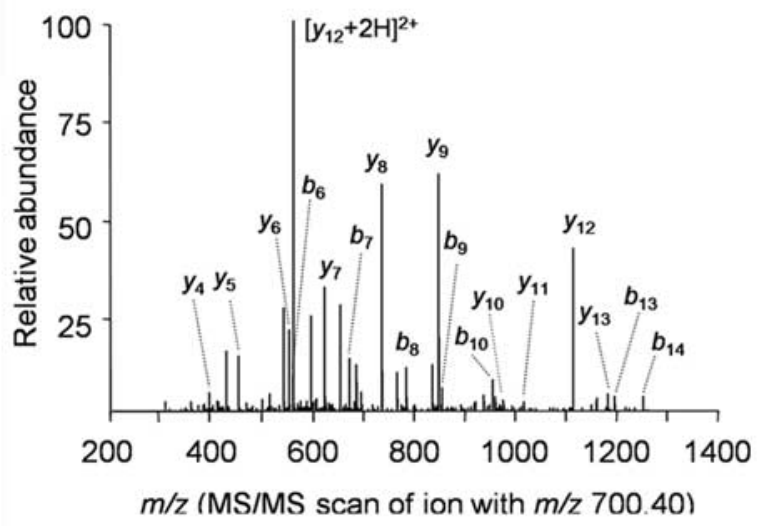

Figure 1. Characterization of LR11 exon 4 deletion variant in $L r 11^{-1-}$ mice. $A$, Top, Sequencing results of purified RT-PCR products from LR11 wild-type and LR11 mutant mice were aligned and show a full deletion of exon 4 messenger RNA sequence in $L r 11^{-/-}$samples. Bottom, Single stranded CDNA from $L r 11^{+/{ }^{+}}, L r 11^{+/-}$, and $L r 11^{-/-}$brain samples was amplified between exon 3 and exon 5 (left) and within exon 4 (right) and visualized by standard agarose gel electrophoresis. The expected size of the reaction products was 300 nucleotides and 160 nucleotides, respectively. In exon 3 to exon 5 RT-PCR, the expected 300 bp band is observed in $L r 11^{+/+}$sample an additional smaller band is observed $L r 11^{+/-}$samples and is also evident in $L r 11^{-/-}$samples. A fully intact exon 4 reaction product is detected in $L r 11^{+/+}$and $L r 11^{+/-}$samples but cannot be detected in $L r 11^{-/-}$samples. $\boldsymbol{B}$, Western blotting for LR11 with a rabbit anti-LR11 C-terminal antibody reveals LR11 protein expression in LR11 wild-type $(+/+)$ and LR11 deficient $(-/-)$ mice (arrow; left panel). This protein migrates at the same molecular weight as overexpressed LR11 in HEK cell lysates (HEK/LR11). The LR11-specific band in these samples can be eliminated by preadsorption of the LR11-CT antibody with free LR11 C-terminal peptide (arrow; right panel). C, Summary of mass spectrometry results collected from $L r 11^{+/-}$and $L r 11^{-/-}$tissue samples: 14 individual LR11 peptides were identified in $+/-$ brain and 3 LR11 peptides were identified in $L r 11^{-I-}$ brain. Sequence information for the 3 peptides identified in $L r 11^{-1-}$ brain is provided. $\boldsymbol{D}$, Representative spectrum of fully tryptic LR11 peptide ESAPGLIIATGSVGK identified in $L r 11^{-1-}$ tissue by mass spectrometry.

from exons 3-7. The upper and lower bands corresponding to the wild-type and mutant RT-PCR products were separated by agarose electrophoresis, recovered from the gel, and sequenced. DNA sequencing results confirm that the genomic region corresponding to exon 4 is absent in the product generated from the mutant $L r 11$ allele (Fig. $1 A$ ). In $\operatorname{Lr} 11^{\Delta E x 4}$ mutant mice, the $3^{\prime}$ end of exon 3 is spliced directly onto the $5^{\prime}$ end of exon 5 through a transcriptional event that has not been reported in wild-type animals. This unexpected and hitherto unreported splicing event results in LR11 message that is exactly 162 bp's smaller and a protein that lacks 54 residues within the $\mathrm{N}$-terminal region of the VPS10p domain.

SDS-PAGE/Western blot of total mouse brain lysates confirms the presence of low levels of a truncated LR11 variant in Lr11 ${ }^{-/-}$brain lysates probed with an N-terminal domain antibody recognizing the VPS10p domain (data not shown) and an antibody raised to the LR11 C terminus (Fig. $1 B$ ). Preadsorption of rabbit anti-LR11 CT with LR11 CT peptide eliminates the observed $250 \mathrm{kDa}$ band in Western blotted $\mathrm{Lr}_{11}{ }^{-/-}$samples (Fig. $1 B)$. To further characterize the protein recognized by anti-LR11 antisera in $+/-$ and $-/-$ mice, LR11 from cortical homogenates was purified by immunoprecipitation and analyzed by tandem mass spectrometry (MS/MS). The LR11-containing SDS gel band was trypsinized and the digested peptides were fractionated by capillary reverse phase HPLC. Eluted peptides were ionized and transferred into an on-line mass spectrometer, where they were further separated based on mass-to-charge ratio $(\mathrm{m} / \mathrm{z})$. The detected peptide ions were then selected sequentially and fragmented to generate specific MS/MS spectra containing its sequence information. After database search, we identified LR11 as the major protein in both samples; 14 individual LR11 peptides were sequenced a total of 15 times (spectral counts) in $\mathrm{Lr} 11^{+/-}$ brain and 3 individual peptides were sequenced a total of 4 times in $\operatorname{Lr} 11^{-1-}$ brain (Fig. 1C). Three fully tryptic peptides (R.ENQEVILEEVR.D; K.ESAPGLIIATGSVGK.N; K.ITTVSLSAPDALK.I) from both sample were matched and a representative spectrum is shown in Figure $1 D$. Consistent with the deletion of exon 4 in Lr11 mRNA, we detected one peptide (K. ASNLLLGFDR.S) from exon 4 region in the $+/-$ sample digested by trypsin, but we did not detect this peptide in the trypsin-digested LR11-/- sample. Identification of distinct LR11 peptides in Lr $11^{-/-}$brain by mass-spectometry provides definitive evidence for the residual protein expression of the $\operatorname{Lr} 11^{\Delta E x 4}$ variant in this mouse model.

Immunohistochemistry for LR11 in $\operatorname{Lr}_{11}{ }^{\Delta E x 4}$ mouse brain shows that staining intensity is markedly reduced compared with control brain (Fig. 2A). Preadsorption of anti-LR11 with the C-terminal peptide immunogen (PA) eliminates staining on 


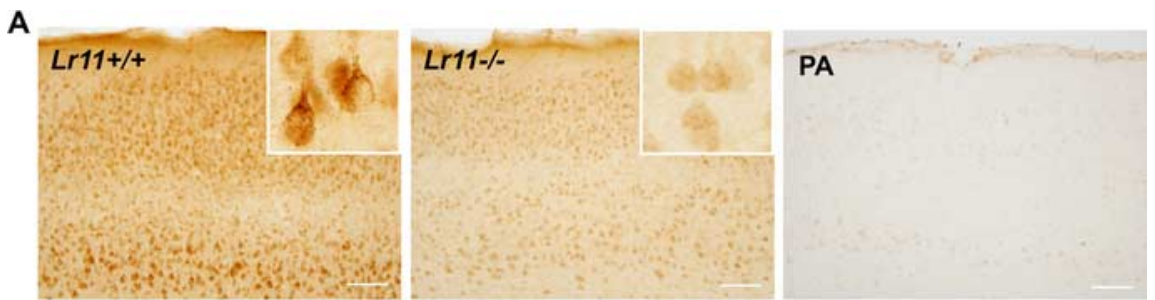

B

$+/++/--/-+/++/--/-+/++/--1-+/++/--/-$
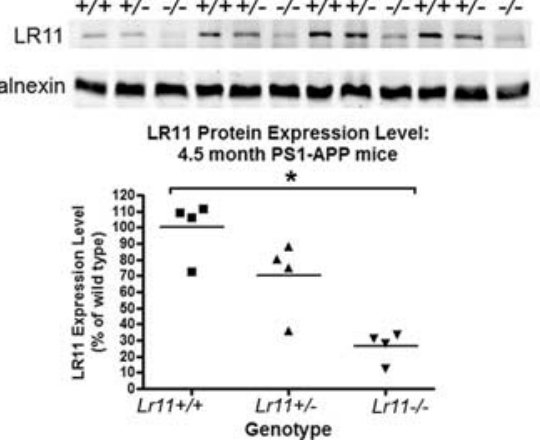

C Relationship between LR11 $\triangle$ Ex4 and secreted $A \beta 40$

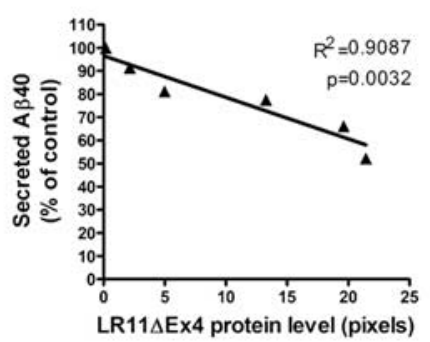

Figure 2. $\mathrm{LR} 11^{\Delta \mathrm{Ex} 4}$ protein expression in brain and effect on $\mathrm{A} \beta$ secretion. $A$, Immunohistochemistry was used to visualize LR11 protein expression pattern in $\mathrm{Lr}^{+1^{+/+}}$(top left) and $\mathrm{Lr}_{11}{ }^{-/-}$(top middle) coronal cortical sections. LR11 immunoreactivity (brown) is observed in both $\mathrm{LrI1}^{+/+}$and $\left.\mathrm{Lr}\right)^{-/-}$tissue sections, while intensity of immunoreactivity is markedly reduced in $\mathrm{Lrr1}^{-{ }^{-}-}$brain. High magnification (insets) shows punctate somatodendritic LR11 immunoreactivity in both $\mathrm{LrI1}^{+/+}$and $\mathrm{LrnT}^{-{ }^{-}}$mice. Antibody specificity is demonstrated by eliminating immunoreactivity with preadsorption (PA; top right) of the LR11 C terminus (CT) antibody with free CT peptide before incubation with tissue. Scale bar, $100 \mu \mathrm{m} . \boldsymbol{B}$, LR11 protein is detected by Western blot of 4.5-month-old $\mathrm{Lr}^{11^{+/+}}, \mathrm{Lr} \mathrm{I}^{+/-}$, and $\mathrm{Lr} 11^{-/-}$cortex. Calnexin is shown to demonstrate equal loading. Densitometric quantitation of LR11 band intensity reveals significant differences in LR11 protein level across genotypes ( $p=$ 0.0154). C, The $L r 11^{\Delta E x 4}$ protein was cloned into pcDNA and transiently transfected at increasing doses into HEK293 cells. Lr1 ${ }^{\Delta E \times 4}$ overexpression induces a dose-related decrease in $A \beta$ secretion.

mouse brain sections (Fig. $2 \mathrm{~A}$ ), illustrating that the immunoreactivity observed in LR11 $\mathrm{Ex} 4$ tissue is not attributable to nonspecific primary or secondary antibody binding to tissue. Quantitative Western blotting (Fig. 2B) for LR11 expression in $\mathrm{Lr}_{1} 1^{+/+}, \mathrm{LrI1}^{+/-}$, and $\mathrm{LrI1} 1^{-/-}$animals shows that the $\mathrm{Lr} 11^{-/-}$ mice express the truncated $\operatorname{Lr}_{1} 1^{\Delta E x 4}$ form of LR11 at a level at least fourfold lower than the level of full-length LR11 of the wildtype mice $(p<0.05)$, and heterozygous mice carrying both the wild-type and mutant Lr11 alleles are intermediate in protein expression level (Kruskal-Wallis, ANOVA, $p=0.0154$ ).

To address the function of the mutant receptor, we cloned $\operatorname{Lr} 11^{\Delta E x 4}$ into the pcDNA 3.1 mammalian expression vector and assessed the effect of $\operatorname{Lr} 11^{\Delta E x 4}$ on $A \beta$ secretion from HEK cells. Similar to the wild-type receptor, increasing doses of $L r 11^{\Delta E x 4}$ led to a dose-dependent decrease in secreted A $\beta 40\left(r^{2}=0.908, p=\right.$ 0.0032 ) (Fig. 2C). These data suggest that the mutant receptor retains the ability to regulate $\mathrm{A} \beta$ formation. In summary, LR11 mutant mice lack the wild-type receptor but express low levels of an LR11 species missing part of the VPS10p domain encoded by Exon 4 . While the mutant receptor is poorly expressed, it appears to retain functional activity with respect to $\mathrm{A} \beta$ production. Thus, we conclude that $L r 11^{\Delta E x 4}$ mutant mice are not LR11 knock-outs per se, but are an excellent in vivo model of LR11 deficiency.

To determine the in vivo effects of LR11 deficiency on amyloidogenesis, mice heterozygous for the $\operatorname{Lr} 11^{\Delta E x 4}$ allele $\left(\operatorname{Lr} 11^{+/-}\right)$ were crossed with mice carrying mutant PSEN1 with Exon 9 deletion (PS1 $1 \mathrm{E} 9)$ and the K595M/N596L human APPswe. Genotypes of interest for this study were PS1/APP-positive mice homozygous for both wild-type $\operatorname{Lr} 11$ alleles $\left(\mathrm{Lr}_{11}{ }^{+/+}\right)$, heterozygous for wild-type $\operatorname{Lr} 11$ and mutant $\operatorname{Lr} 11^{\Delta E x 4}\left(\operatorname{Lr}_{11} 1^{+/-}\right)$, and homozygous $\operatorname{Lr} 11^{\Delta E x 4}$ mutants $\left(\operatorname{Lr}_{11}^{-/-}\right)$. Amyloid mea- sures were taken from cortex of 3, 4.5, 6, and 12-month-old PS1/APP/Lr11 $1^{+/+}$and $P S 1 / A P P / L r 11^{-1-}$ animals. Brain lysates were subjected to sequential SDS and formic acid extraction, and $\mathrm{A} \beta 40$ and $\mathrm{A} \beta 42$ levels were determined by sandwich ELISA. See supplemental Table 1, available at www.jneurosci.org as supplemental material, for summary statistics, including the gender and number of animals analyzed at each age and raw values from all fractions measured. The variance in the PS1/APP animals is not surprising, given the published phenotypic variability of this transgenic animal model (Jankowsky et al., 2001, 2004; van Groen et al., 2006). However, PS1/APP animals on the LR11deficient background often exhibited a statistically higher variance than the LR11 wild-type animals, possibly indicating individual differences in compensating for LR11 deficiency. The majority of animals used in this study were female $(n=34)$, but when low numbers precluded statistical comparisons, some males were added $(n=14)$ and matched as best as possible between groups.

LR11-deficiency led to a substantial increase in SDS-soluble and formic-acid soluble $A \beta$ in brain. Figure $3 A$ shows increasing total $A \beta$ levels with age (plotted as the natural $\log$ of raw values) in PS1/APP/ Lr $11^{+/+}$and PS1/APP/Lr11 $1^{-/-}$animals. Significant differences in A $\beta$ levels between $L r 11^{+/+}$and $L r 11^{-1-}$ mice are observed at 3 $(p=0.0381), 4.5(p=0.0079)$ and 6 months $(p=0.048)$, suggesting that loss of LR11 in PS1/APP mice accelerates the early accumulation of $\mathrm{A} \beta$ (two-way ANOVA genotype effect $p=$ 0.0005 ) (Fig. $3 A$; supplemental Table 1, available at www. jneurosci.org as supplemental material). This effect did not vary with the species of $A \beta$ measured ( $A \beta 40$ vs $A \beta 42$ ), nor with the fraction measured (SDS-soluble vs formic acid soluble). Compared with LR11 wild-type mice, LR11 deficiency in PS1/APP mice increased total $\mathrm{A} \beta$ levels by $\sim 700 \%$ at 4.5 months of age and $\sim 200 \%$ at 6 months of age. At 12 months of age, all measures of A $\beta$ are similar between $\operatorname{Lr} 11^{+/+}$and $L r 11^{-/-}$animals (Fig. $3 A$, supplemental Table 1, available at www.jneurosci.org as supplemental material). At this advanced stage of cortical amyloidosis, the aggressive nature of the PS1 and APP mutations appears to overwhelm the effects of LR11 loss.

To examine whether LR11 loss could exacerbate amyloid plaque pathology, histological evaluation of plaque burden was performed. Figure $3 D$ illustrates amyloid plaque accumulation in 4.5, 6 and 12 month-old PS1/APP mice with $\left(\mathrm{Lr}_{11}{ }^{+/+}\right)$and without $\left(\operatorname{Lr} 11^{-1-}\right)$ wild-type LR11 expression. A $\beta 42$-stained surface area (Fig. $3 B$ ) and plaque counts of thioflavine-S-positive amyloid deposits (Fig. 3C) on sagittal brain sections were used to quantify the effect of $\operatorname{Lr} 11$ genotype on the development of amyloid plaque pathology in PS1/APP mouse brain. Similar to observed differences in A $\beta$ levels, LR11's influence on plaque deposition is most pronounced at early stages of pathology. Amyloid deposition, as measured by A $\beta 42$ staining in cortex and hippocampus, increases by two to threefold in LR11-deficient animals at 4.5 months $(p=0.0286)$ and 6 months $(p=0.0020)$ 
compared with wild-type littermates (Fig. 3B) (two-way ANOVA interaction effect $p<0.0001)$. Total plaque counts in Lr $11^{-1-}$ mice are significantly elevated at 3 months $(p=0.0379)$ and 6 months of age $(p=0.002)$ (Fig. 3C) (two-way ANOVA genotype effect $p=0.0070)$. As observed with ELISA measurements of $\mathrm{A} \beta$, both $\mathrm{A} \beta 42$ immunostaining and thioflavine-S staining in cortex and hippocampus of PS1/APP/Lr11 ${ }^{+/+}$and PS1/ $A P P / L r 11^{-/-}$animals are comparable at 12 months of age (Fig. $3 B, C$ ), suggesting that LR11 deficiency accelerates amyloidosis but does not increase maximal amyloid burden.

Unexpectedly, some of the largest differences in amyloid measures between $\mathrm{LrI1}^{+/+}$and $\mathrm{Lr} 11^{-/-}$animals were found in cerebellum. Compared with control mice, increases in $A \beta 42$-stained surface area are evident in PS1/APP/Lr11 $1^{-1-}$ mice at 6 months $(p=0.0295)$ and 12 months of age ( $p=0.0357)$ (cerebellar plaque pathology was not consistently observed at 3 month of age) (Fig. 4A) (two-way ANOVA genotype effect $<0.0001)$. Even at 12 months of age, when the impact of LR11 loss appears to be diminished in cortex and hippocampus, there was a $\sim 5$-fold increase in cerebellar $\mathrm{A} \beta 42$-stained surface area. Moreover, quantitative ELISA measures of cerebellar extracts at 12 months revealed a threefold increase in A $\beta 40$ levels in $\mathrm{LrI1}^{-/-}$animals compared with $\mathrm{Lr} 11^{+/+}$littermates (Fig. $\left.4 B\right)(p=$ $0.0381)$. Amyloid deposition in the cerebellum of $P S 1^{\triangle E 9} / A P P^{\text {swe }}$ mice lags behind cortex and hippocampus, and loss of LR11 in PS1/APP mutant mice dramatically increases cerebellar amyloid pathology in 12-month-old mice.

To establish whether LR11 can regulate $\mathrm{A} \beta$ accumulation in a dose-dependent manner, we examined $\operatorname{Lr} 11^{+/+}, \operatorname{Lr} 11^{+/-}$ and $L r 11^{-1-}$ mice at 4.5 months of age. In cortex, total $A \beta 42$ levels from the 3 groups were significantly different (Fig. 5A) (ANOVA $p=0.0490)$. A $\beta 42$ levels were increased $\sim 9$-fold in LR11 deficient homozygotes compared with wild-type $\left(\operatorname{Lr} 11^{-1-}\right.$ $=858.9 \pm 347.1 \mathrm{pg} / \mathrm{mg}$ tissue vs $\operatorname{Lr} 11^{+/+}=94.51 \pm 31.11 ; p<$ $0.05)$, while $\mathrm{A} \beta 42$ levels in heterozygotes were intermediate $\left(\mathrm{Lr} 11^{-1-}=230.3 \pm 99.33 \mathrm{pg} / \mathrm{mg}\right.$ tissue $)$ and not significantly different from either $\mathrm{LrI1}^{+/+}$or $\mathrm{Lr} 11^{-1-}$ mice. There also appears to be an LR11 expression level effect on amyloid plaque accumulation. Significant differences in thioflavine-S plaque counts were seen across the three genotypes (Fig. 5B) (ANOVA $p=0.0388)$, again with $L r 11^{+/-}$mice (54.63 \pm 24.79 plaques) exhibiting a nonsignificant intermediate phenotype between $\operatorname{Lr}_{1} 1^{+/+}(34.15 \pm 13.89)$ and $\operatorname{Lr}_{1} 1^{-/-}$mice $(76.00 \pm 12.10)$ $\left(\mathrm{Lr}_{11}{ }^{+/+}\right.$vs $\left.\operatorname{Lr} 11^{-/-} p<0.05\right)$. Across all three genotypes, LR11 protein level, as measured on immunoblots, inversely correlates with $\mathrm{A} \beta 42$ staining in cortex (Fig. $5 C)\left(R^{2}=0.433, p=0.0278\right)$.
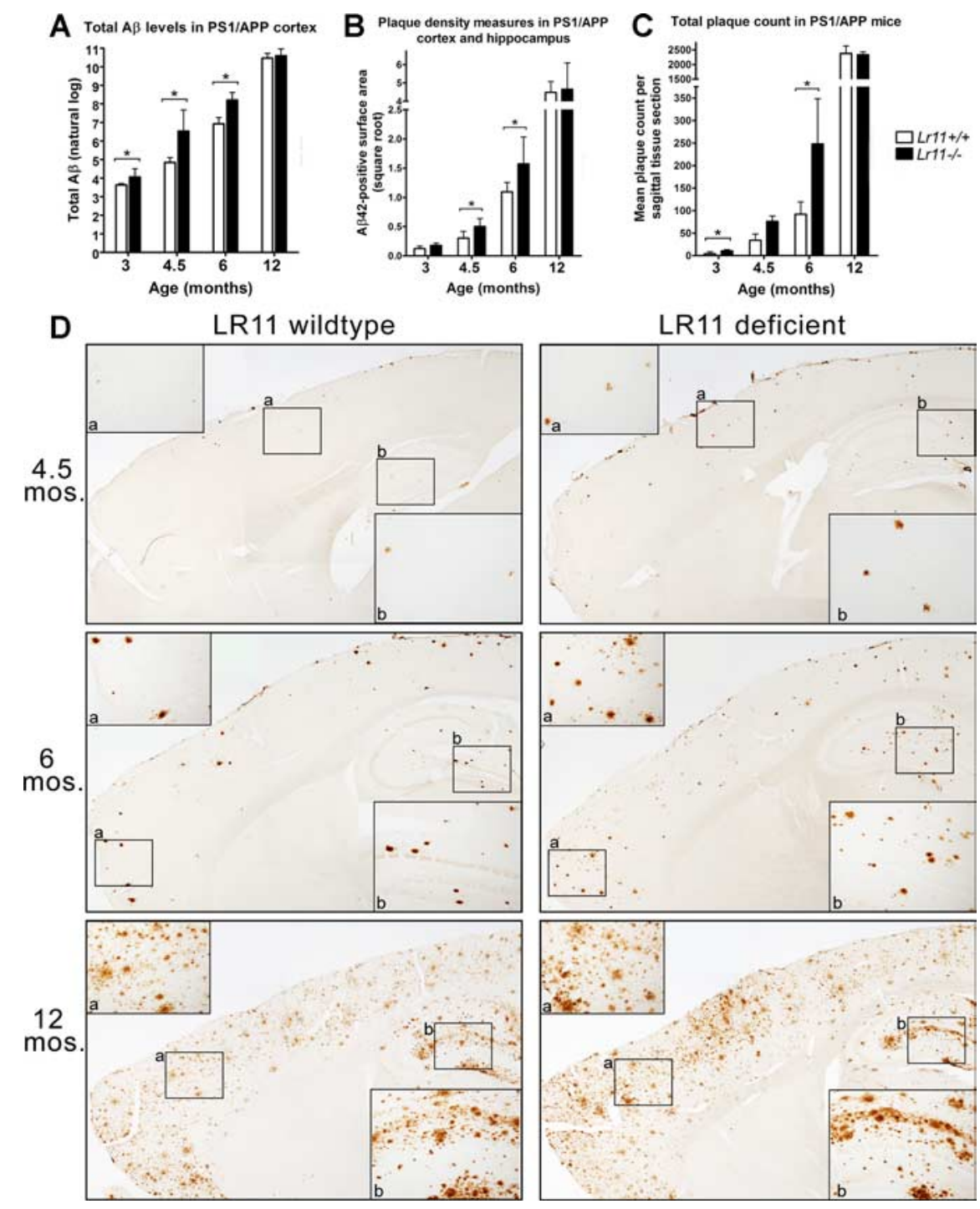

Figure 3. $\beta$-amyloid measures in $L r 11^{+/+}$and $L r 11^{-/-}$cortex and hippocampus. $A$, ELISA-quantification of total $A \beta$ levels values (see supplemental Table 1, available at www.jneurosci.org as supplemental material, for raw values). $\operatorname{Lr} 11^{-1}$ mice exhibit significant increases in total $A \beta$ levels at $3(p=0.038), 4.5(p=0.0079)$ and 6 months of age $(p=0.048)$. $B_{,}$ (mean surface area (pixels) of $A \beta 42$-positive immunoreactivity per tissue section] is significantly inmice at $4.5(p=0.0286)$ and 6 months of age $(p=0.002)$.C Total plaque count is significantly increased in $L r 11^{-1-}$ mice at $3(p=0.0379)$ and 6 months $(p=0.002)$. D, Qualitative images of $A \beta 42$-stained amyloid deposits (brown) in $L r 11^{+/+}$(left) and $L r 11^{-/-}$(right) cortex and hippocampus at 4.5, 6, and 12 months of age. Boxed regions of cortex (a) and hippocampus $(\boldsymbol{b})$ are magnified and shown as corresponding insets.

The strong inverse correlation between LR11 protein levels and $\mathrm{A} \beta 42$ accumulation suggests direct regulation of $\mathrm{A} \beta$ production by LR11.

We hypothesized that the mechanism underlying the enhanced amyloid pathology in the $\operatorname{Lr} 11^{-1-} \times$ PS1/APP mice was increased amyloidogenic processing of APP. To test this, immunoblot analysis of APP metabolites was performed in a subset of PS1/APP/Lr11 $1^{+/+}(n=7)$ and $\operatorname{Lrl1}^{-/-}(n=6)$ cortical tissue samples. Full-length APP levels were unchanged $\left(\mathrm{Lr}_{1} 1^{+/+}=\right.$ $100.0 \%+/-15.16$ vs $\operatorname{Lrl1}^{-/-}=124.3 \%+/-22.26 ; p=$ 0.3740 ), but we observed increased accumulation of the soluble $\alpha$-cleaved secreted APP (APPs $\alpha$ ) in $L r 11^{-1-}$ cortical tissue ( $p=$ $0.0161)$, decreased levels of membrane-associated CTF $\alpha$ ( $p=$ 0.0133 ), and decreased CTF $\beta$ ( $p=0.0076$ ) (Fig. 6A). We hypothesize that lower steady-state levels of CTFs reflect increased 


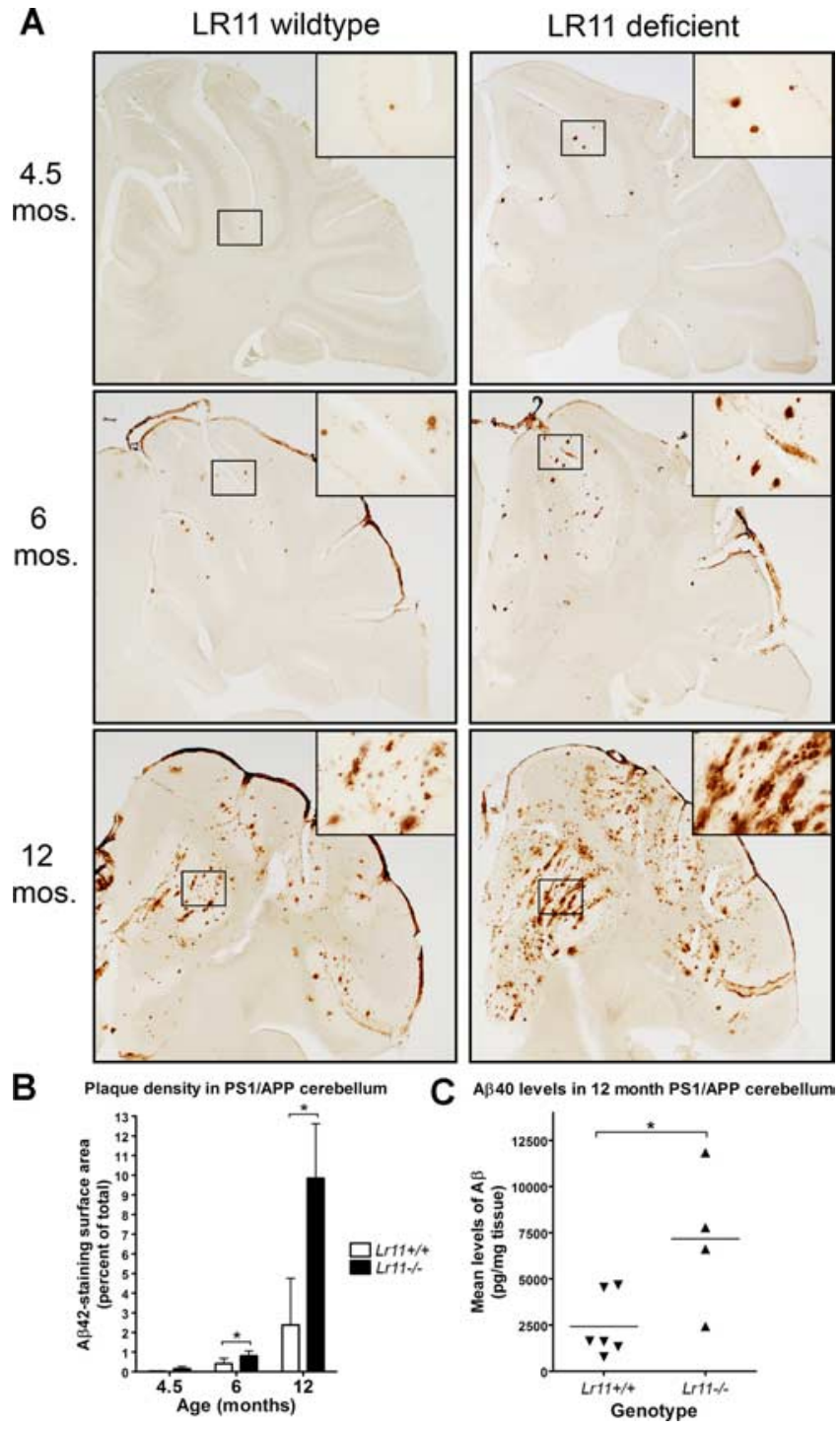

Figure 4. $\beta$-amyloid measures in $L r 11^{+/+}$and $L r 11^{-1-}$ cerebellum. $A$, Qualitative images of $A \beta 42$-stained sagittal sections of $L r 11^{+/+}$(left) and $\mathrm{Lr}{ }^{-/-}$(right) cerebellum at 4.5,6, and 12 months of age. Boxed regions are magnified and shown as corresponding insets. $\boldsymbol{B}$, Amyloid plaque density [mean surface area (pixels) of $A \beta 42$-positive immunoreactivity per tissue section] is significantly increased in $L r 11^{-1-}$ mice at $6(p=0.0286)$ and 12 months of age ( $p=0.0357)$. C, ELISA-quantification of A $\beta 40$ levels ( $\mathrm{pg} / \mathrm{mg}$ tissue) is significantly elevated in $L r 11^{-/-}$cerebellum (black bars) compared with $L r 11^{+/+}$littermates (white bars) at 12 months of age ( $p=0.0381)$.

$\gamma$-secretase processing of the membrane-bound stubs, which leads to increased generation of the $\mathrm{A} \beta$ peptide.

Additionally, we used embryonic cortical cultures prepared from $\mathrm{Lrl1}^{+/+}$and $\mathrm{Lr}_{1} 1^{-/-}$mice to assess acute levels of APP metabolites. Rather than analyze an FAD-linked variant, we sought to establish whether LR11 loss could influence normal APP695 processing, a question that is more relevant to sporadic Alzheimer's disease. Using lentiviral-mediated gene delivery, human wild-type APP695 was transduced into primary cortical cultures prepared from $\mathrm{Lr} 11^{+/+}$and $\mathrm{Lr} 11^{-/-}$embryos (three experiments were performed in quadruplicate). In these experiments, total APP expression was only increased by twofold to threefold over endogenous murine APP (data not shown), reducing the potential for overexpression artifacts. Analysis of APP metabolites was performed by Western blot from conditioned media and cell lysates (Fig. 6B). We found no difference in transduction efficiency or expression of full-length human APP in cortical cultures $\left(\operatorname{Lr} 11^{+/+}=100.0 \%+/-6.02\right.$ vs $\operatorname{Lr}^{-1} 1^{-/-}=104.2 \%$ $+/-4.29, p=0.3856)$. However, secreted APP, normalized to cell-associated APP, was increased over twofold in $\mathrm{Lr}_{1}{ }^{-1-}$ conditioned media samples, including both APPs $\alpha$ (increased by $227.5 \% ; p=0.0307$ ) and APPs $\beta$ (increased by $224.8 \%$; $p=$ $0.0094)$. In contrast to cortical tissue analysis, we did not observe significant alterations in secreted $\mathrm{A} \beta$ (data not shown; $p=$ $0.3155), \operatorname{CTF} \alpha(p=0.863)$ or $\operatorname{CTF} \beta(p=0.2840)$ in these primary culture experiments (Fig. $6 B$ ). It is possible that the infection protocol and conditioning period was not long enough to resolve alterations in the $\gamma$-secretase-mediated processing events that control the metabolism of CTFs and generation of $\mathrm{A} \beta$. Nonetheless, the robust effects on secretion of APPs $\alpha$ and APPs $\beta$ strongly suggests LR11-deficiency in neurons acutely increases the overall processing, including the amyloidogenic $\beta$-secretasemediated processing, of wild-type human APP. Combined, the in vivo and in vitro measures of APP metabolites from $\mathrm{Lrl1}^{-1-}$ mice strongly implicate LR11 as a regulator of APP processing in neurons.

\section{Discussion}

The $\operatorname{Lr} 11^{\Delta E x 4} \times P S 1^{\Delta E 9} / A P P^{\text {swe }}$ mice represent an animal model that recapitulates the deficiency of LR11 observed in Alzheimer's disease. In cortex and hippocampus, LR11 loss potently accelerates amyloid accumulation at the earliest stages of amyloid deposition. At 4.5 months, PS1/APP transgenic mice homozygous for $\operatorname{Lr} 11^{\Delta E x 4}$ have a sevenfold increase in amyloid levels and resemble 6 month-old PS1/APP mice expressing wild-type LR11. The connection between LR11 expression and $A \beta$ deposition is reinforced by the intermediate phenotype of heterozygous mice $\left(\mathrm{Lr}_{11}^{+/-}\right)$and the inverse relationship between LR11 protein level and plaque formation in PS1/APP mouse brain. While we cannot rule out the possible influence of LR11 in the clearance or degradation of $\mathrm{A} \beta$, alterations in steady-state and acute measures of APP metabolites in $\mathrm{Lr} 11^{-/-}$mice suggests that loss of LR11 increases the rate of processing of the APP holo-protein. In a complementary study, a modest increase in amyloid deposition was found in a separate model of human amyloidosis in transgenic PDAPP mice (Rohe et al., 2008). The accelerated development of neuropathology in LR11 deficient mice provides direct evidence that LR11 expression is intimately tied to molecular events underlying amyloid accumulation and deposition in vivo.

In older animals, the influence of LR11 loss in cortex appears to be overwhelmed by the aggressive PS1 and APP mutations that drive amyloidosis, but cerebellar amyloid accumulation continues to show significant differences in LR11 deficient mice (Fig. 5). Pathologic amyloid deposition in cerebellum is rarely reported in human $\mathrm{AD}$ or transgenic mouse models, but in a handful of FAD variants, including the $P S 1^{\Delta E 9}$ mutation, prominent amyloidosis and plaque formation have been observed in cerebellum of affected individuals and $P S 1^{\triangle E 9} / A P P^{\text {swe }}$ mice (Mann et al., 2001; van Groen et al., 2006). It is generally accepted that the cerebellum is less affected by pathology than other regions in sporadic $\mathrm{AD}$, but this observation is not well understood. What is different about cerebellum that seemingly protects this region from $\mathrm{AD}$ pathology? One difference may be related to LR11 expression; we previously reported that cerebellum is spared of LR11 loss in AD brain (Offe et al., 2006). Given its intimate relationship with APP and $\mathrm{A} \beta$, preserved expression of LR 11 in human cerebellum may contribute to this phenomenon.

Previous reports by us and other groups have demonstrated that LR11 can physically interact with APP and modulate the 
processing of exogenously expressed APP. In addition to its interactions with APP, LR11 has also been linked to both BACE1 and $\gamma$-secretase, the two enzymes that are necessary for the cleavage of APP and release of $\mathrm{A} \beta$ (Böhm et al., 2006; Nyborg et al., 2006; Spoelgen et al., 2006). We and others have also reported that exogenously expressed LR11 directs the trafficking of APP away from amyloidogenic cellular compartments in vitro (Andersen et al., 2006; Offe et al., 2006; Spoelgen et al., 2006; Rogaeva et al., 2007; Schmidt et al., 2007). This hypothesis is supported by findings that the cytoplasmic domain of LR11 interacts with Golgi-localized, Gamma-ear-containing, Arf-binding (GGA) adaptors that regulate membrane traffic between the Golgi and endocytic compartments (Nielsen et al., 2001; Jacobsen et al., 2002) and that disrupting interaction of LR11 with GGA1 alters APP processing fates (Schmidt et al., 2007). A role for LR11 in control of APP trafficking and processing is also supported by our observation that LR11 overexpression in vitro increases association of APP with endosomal markers, increases non- $\gamma$-secretasecleaved APP C-terminal fragments, and decreases $\mathrm{A} \beta$ production (Offe et al., 2006).

The in vitro evidence discussed above suggests that LR11 has a primary influence on APP processing, rather than the clearance or degradation of the $\mathrm{A} \beta$ peptide. In the current study, we provide direct evidence linking reduced LR11 expression to enhanced amyloidosis and altered APP processing in intact animals and primary neurons. Our analyses of APP metabolites in vivo are consistent with findings in cellular models, which suggest that loss of LR11 increases secretase processing of APP. Along with increased A $\beta, P S 1 / A P P /$ Lr $11^{-/-}$mice exhibited increased APPs $\alpha$ and decreased CTF levels in cortical tissue, implying either the increased exposure of APP to secretases and/or increased activity of the enzymes. While changes in BACE1cleaved APPs $\beta$ did not reach significance in cortex, primary cortical neurons from $\mathrm{Lr}_{1} 1^{+/+}$and $\mathrm{Lr} 11^{-/-}$embryos revealed twofold increases in secretion of both $\alpha$ and $\beta$-secretase cleaved APP fragments. Our findings in the $P S 1^{\triangle E 9} / A P P^{\text {swe }}$ mice coincide nicely with those from another recent study in which we found increased APPs levels in the $\mathrm{Lr}_{11} 1^{\Delta E x 4}$ mouse crossed to the PDAPP line (Rohe et al., 2008). Therefore, the exacerbated $\mathrm{A} \beta$ phenotype in the LR11-deficient mice is better explained by $\mathrm{APP}$ processing changes than by an effect on $\mathrm{A} \beta$ clearance.

The relevance of LR1 1 loss in human brain is just beginning to be established. Although the temporal sequence of disease-
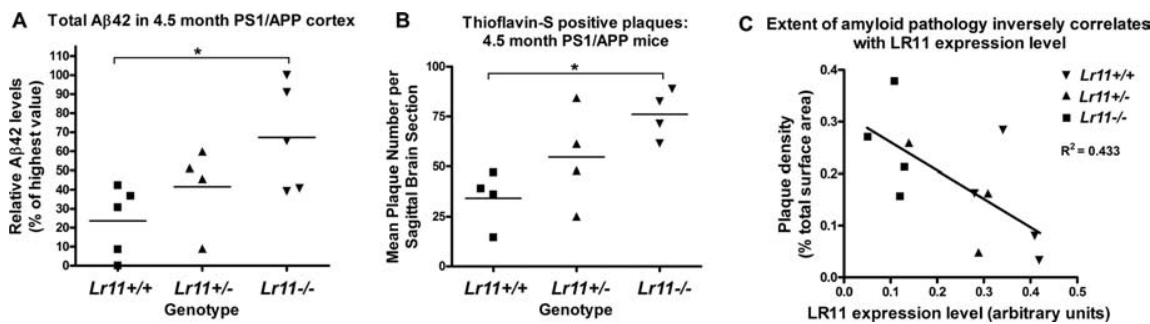

Figure 5. LR11 gene-dose effects on pathological amyloid measures in 4.5-month-old mice. $\boldsymbol{A}$, ELISA-measured A $\beta 42$ levels are significantly different across $L r 11^{+/+}, L r 11^{+/-}$, and $L r 11^{-/-}$genotypes at 4.5 months of age $(p=0.049) \cdot L r 11^{-1-}$ mice have significantly higher $A \beta 42$ levels compared with $L r 11^{+/+}$mice $(p<0.05)$. $L r 11^{+/-}$mice are intermediate and not significantly different from $L r 11^{+/+}$or $L r 11^{+/-}$littermates. $B$, Total plaque count is significantly different across $L r 11^{+/+}$, $L r 11^{+/-}$, and $L r 11^{-/-}$genotypes ( $\left.p=0.0388\right)$. $L r 11^{-/-}$mice exhibit more thioflavine-S-positive plaques per tissue section than $L r 11^{+/+}$littermates $(p<0.05)$. $L r 11^{+/-}$mice are intermediate and not significantly different from $L r 11^{+/+}$or $L r 11^{-/-}$ mice. $C$, Across all genotypes, amyloid plaque density [mean surface area (pixels) of A $\beta 42$-positive immunoreactivity per tissue section] inversely correlates with LR11 expression levels measured by Western blot ( $p=0.0278$ ).
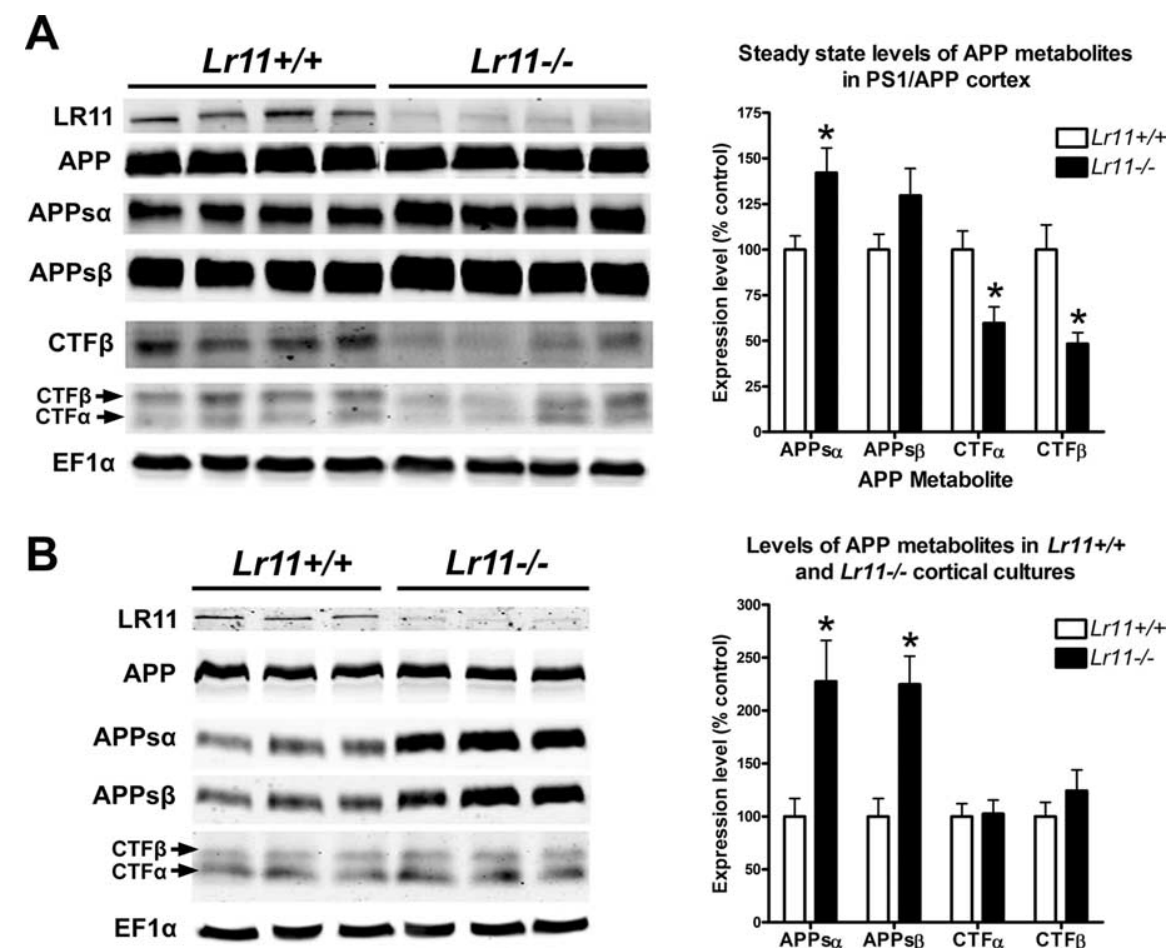

Figure 6. APP metabolite analysis in cortical tissue and primary cortical neurons from $L r 11^{+/+}$and $L r 11^{-1-}$ mice. $A$, Western blot and densitometric quantitation of steady-state APP and relevant APP metabolites in a subset of $L r 11^{+/+}(n=7)$ and $\mathrm{Lr}^{-1}{ }^{-1-}(n=6)$ cortical tissue samples. Membrane proteins and soluble proteins were fractionated by differential centrifugation and blotted with a panel of APP antibodies, including ( 8 to visualize full-length APP and CTFs, 6E10 to visualize APPs $\alpha$ and CTF $\beta$, and 192swe to specifically detect the Swedish form of APPs $\beta$. For quantitation, APPs levels were normalized to levels of the unrelated soluble protein EF1 $\alpha$ and CTF levels were normalized to full-length APP. $L r 11^{-1-}$ mice exhibit $\sim 40 \%$ increase in APPs $\alpha(p=0.0161)$ and $\sim 50 \%$ decrease in both CTF $\alpha(p=0.0133)$ and CTF $\beta(p=0.0076)$. $B$, Western blot and densitometric quantitation of lentivirally transduced APP and APP metabolites from primary cortical culture lysates and conditioned media ( 3 independent experiments performed in quadruplicate). Overexpressed wild-type human APP695 is detected by the human specific $6 \mathrm{E} 10$ antibody and other metabolites were detected by the same panel of antibodies described above (with the exception of 192wt to visualize wild-type APPs $\beta$ ). For quantitation, APPs and (TF levels were normalized to over-expressed APP in each sample. $\mathrm{Lr11}{ }^{-1-}$ cortical neurons express equivalent levels of full-length APP695, but secrete $\sim 2$-fold more APPs $\alpha$ ( $p=0.0307)$ and APPs $\beta$ ( $p=0.0094)$ into the media. Levels of CTFs are unchanged in $L r 11^{-1-}$ cortical lysates. EF1 $\alpha$ is shown to demonstrate loading consistency.

relevant molecular events is difficult to establish from pathological studies, we previously reported that LR11 expression is unaffected by amyloid accumulation in autosomal-dominant, familial AD cases (Dodson et al., 2006). This finding argues that LR11 loss is not simply a downstream consequence of other 
pathological changes, and led us to hypothesize that LR11 loss could be a primary and early event in $\mathrm{AD}$ pathogenesis. Our current findings in LR11-deficient mice strongly support this possibility. In addition, we recently reported results of a postmortem study of LR11 in cases of individuals with mild cognitive impairment (MCI), a clinical condition which often represents prodromal AD. A subset of MCI cases had significantly reduced LR11 expression, suggesting that loss of LR11 occurs before overt clinical symptoms of AD (Sager et al., 2007). The hypothesis that LR11 loss represents a primary event in $\mathrm{AD}$ pathogenesis has been bolstered by genetic studies, which identified a number of single nucleotide polymorphisms in the LR11 gene that were modestly associated with risk of $\mathrm{AD}$ in several ethnic populations (Rogaeva et al., 2007). Interestingly, the reported risk variants are found in noncoding regions, potentially representing promoter or other cis-acting elements that may regulate LR11 expression level. Independent studies have identified genetic association between LR11 variants and cognitive aging (Seshadri et al., 2007), as well as risk of developing $\mathrm{AD}$ in individuals afflicted with Down syndrome, an autosomal-dominant disorder that is marked by duplication of the APP gene locus (Lee et al., 2007a). Subsequent studies using sporadic $\mathrm{AD}$ samples have reported both positive and negative associations of LR11 SNPs with AD (Meng et al., 2007; Tan et al., 2007; Bettens et al., 2008; Lee et al., 2008; Li et al., 2008; Webster et al., 2008). Interpretation of these genetic studies is limited by the lack of consistent association of specific variants with $\mathrm{AD}$ in different populations, and the findings must be confirmed by further independent studies. Nevertheless, the strength of the biological evidence powerfully supports the plausibility of a genetic association between LR11 and risk of common, late-onset forms of $\mathrm{AD}$.

Our demonstration that loss of LR11 influences APP processing and exacerbates amyloid pathology in vivo in a dosedependent manner suggests a tight coupling between LR11 expression and toxic amyloid accumulation. This finding anchors the growing connection between LR11 and causal mechanisms of AD pathogenesis. Neuropathologically, LR11 loss in late-onset, sporadic AD has been implicated as an early and common event in vulnerable neurons of human brain. At the cellular level, LR11 directs the trafficking of APP and inhibits $\mathrm{A} \beta$ production. Further, genetic association studies point to the possibility that LR11 variants mediate late-onset $\mathrm{AD}$ susceptibility. Combined, these observations strongly suggest that neuronal LR11 expression plays a protective role against $\mathrm{AD}$, and moreover, that loss of LR11 in human brain may drive the amyloidogenic disease process. Here, we provide compelling in vivo evidence that LR11 loss is indeed intimately tied to proximal molecular events underlying Alzheimer's disease pathogenesis.

\section{References}

Andersen OM, Reiche J, Schmidt V, Gotthardt M, Spoelgen R, Behlke J, von Arnim CA, Breiderhoff T, Jansen P, Wu X, Bales KR, Cappai R, Masters CL, Gliemann J, Mufson EJ, Hyman BT, Paul SM, Nykjaer A, Willnow TE (2005) Neuronal sorting protein-related receptor sorLA/LR11 regulates processing of the amyloid precursor protein. Proc Natl Acad Sci U S A 102:13461-13466.

Andersen OM, Schmidt V, Spoelgen R, Gliemann J, Behlke J, Galatis D, McKinstry WJ, Parker MW, Masters CL, Hyman BT, Cappai R, Willnow TE (2006) Molecular dissection of the interaction between amyloid precursor protein and its neuronal trafficking receptor SorLA/LR11. Biochemistry 45:2618-2628.

Bettens K, Brouwers N, Engelborghs S, De Deyn PP, Van Broeckhoven C, Sleegers K (2008) SORL1 is genetically associated with increased risk for late-onset Alzheimer disease in the Belgian population. Hum Mutat 29:769-770.
Böhm C, Seibel NM, Henkel B, Steiner H, Haass C, Hampe W (2006) SorLA signaling by regulated intramembrane proteolysis. J Biol Chem 281:14547-14553.

Borchelt DR, Thinakaran G, Eckman CB, Lee MK, Davenport F, Ratovitsky T, Prada CM, Kim G, Seekins S, Yager D, Slunt HH, Wang R, Seeger M, Levey AI, Gandy SE, Copeland NG, Jenkins NA, Price DL, Younkin SG, Sisodia SS (1996) Familial Alzheimer's disease-linked presenilin 1 variants elevate Abeta1-42/1-40 ratio in vitro and in vivo. Neuron 17:1005-1013.

Borchelt DR, Ratovitski T, van Lare J, Lee MK, Gonzales V, Jenkins NA, Copeland NG, Price DL, Sisodia SS (1997) Accelerated amyloid deposition in the brains of transgenic mice coexpressing mutant presenilin 1 and amyloid precursor proteins. Neuron 19:939-945.

Dodson SE, Gearing M, Lippa CF, Montine TJ, Levey AI, Lah JJ (2006) LR11/SorLA expression is reduced in sporadic Alzheimer disease but not in familial Alzheimer disease. J Neuropathol Exp Neurol 65:866-872.

Ehehalt R, Keller P, Haass C, Thiele C, Simons K (2003) Amyloidogenic processing of the Alzheimer beta-amyloid precursor protein depends on lipid rafts. J Cell Biol 160:113-123.

Gandy S, Petanceska S (2000) Regulation of Alzheimer beta-amyloid precursor trafficking and metabolism. Biochim Biophys Acta 1502:44-52.

Glenner GG, Wong CW (1984) Alzheimer's disease: initial report of the purification and characterization of a novel cerebrovascular amyloid protein. Biochem Biophys Res Commun 120:885-890.

Gralle M, Ferreira ST (2007) Structure and functions of the human amyloid precursor protein: the whole is more than the sum of its parts. Prog Neurobiol 82:11-32.

Hampe W, Riedel IB, Lintzel J, Bader CO, Franke I, Schaller HC (2000) Ectodomain shedding, translocation and synthesis of SorLA are stimulated by its ligand head activator. J Cell Science 113:4475-4485.

Herz J, Bock HH (2002) Lipoprotein receptors in the nervous system. Annu Rev Biochem 71:405-434.

Hirayama S, Bujo H, Yamazaki H, Kanaki T, Takahashi K, Kobayashi J, Schneider WJ, Saito Y (2000) Differential expression of LR11 during proliferation and differentiation of cultured neuroblastoma cells. Biochem Biophys Res Commun 275:365-373.

Jacobsen L, Madsen P, Jacobsen C, Nielsen MS, Gliemann J, Petersen CM (2001) Activation and functional characterization of the mosaic receptor SorLA/LR11. J Biol Chem 276:22788-22796.

Jacobsen L, Madsen P, Nielsen MS, Geraerts WP, Gliemann J, Smit AB, Petersen CM (2002) The sorLA cytoplasmic domain interacts with GGA1 and -2 and defines minimum requirements for GGA binding. FEBS Letters 511:155-158.

Jankowsky JL, Slunt HH, Ratovitski T, Jenkins NA, Copeland NG, Borchelt DR (2001) Co-expression of multiple transgenes in mouse CNS: a comparison of strategies. Biomol Eng 17:157-165.

Jankowsky JL, Fadale DJ, Anderson J, Xu GM, Gonzales V, Jenkins NA, Copeland NG, Lee MK, Younkin LH, Wagner SL, Younkin SG, Borchelt DR (2004) Mutant presenilins specifically elevate the levels of the 42 residue beta-amyloid peptide in vivo: evidence for augmentation of a 42 -specific gamma secretase. Hum Mol Genet 13:159-170.

Lee JH, Chulikavit M, Pang D, Zigman WB, Silverman W, Schupf N (2007a) Association between genetic variants in sortilin-related receptor 1 (SORL1) and Alzheimer's disease in adults with Down syndrome. Neurosci Lett 425:105-109.

Lee JH, Cheng R, Schupf N, Manly J, Lantigua R, Stern Y, Rogaeva E, Wakutani Y, Farrer L, St George-Hyslop P, Mayeux R (2007b) The association between genetic variants in SORL1 and Alzheimer disease in an urban, multiethnic, community-based cohort. Arch Neurol 64:501-506.

Lee JH, Cheng R, Honig LS, Vonsattel JP, Clark L, Mayeux R (2008) Association between genetic variants in SORL1 and autopsy-confirmed Alzheimer disease. Neurology 70:887-889.

Li Y, Rowland C, Catanese J, Morris J, Lovestone S, O'Donovan MC, Goate A, Owen M, Williams J, Grupe A (2008) SORL1 variants and risk of lateonset Alzheimer's disease. Neurobiol Dis 29:293-296.

Ling Y, Morgan K, Kalsheker N (2003) Amyloid precursor protein (APP) and the biology of proteolytic processing: relevance to Alzheimer's disease. Int J Biochem Cell Biol 35:1505-1535.

Ma QL, Teter B, Ubeda OJ, Morihara T, Dhoot D, Nyby MD, Tuck ML, Frautschy SA, Cole GM (2007) Omega-3 fatty acid docosahexaenoic acid increases SorLA/LR11, a sorting protein with reduced expression in 
sporadic Alzheimer's disease $(\mathrm{AD})$ : relevance to $\mathrm{AD}$ prevention. J Neurosci 27:14299-14307.

Mann DM, Takeuchi A, Sato S, Cairns NJ, Lantos PL, Rossor MN, Haltia M, Kalimo H, Iwatsubo T (2001) Cases of Alzheimer's disease due to deletion of exon 9 of the presenilin-1 gene show an unusual but characteristic beta-amyloid pathology known as 'cotton wool' plaques. Neuropathol Appl Neurobiol 27:189-196.

Meng Y, Lee JH, Cheng R, St George-Hyslop P, Mayeux R, Farrer LA (2007) Association between SORL1 and Alzheimer's disease in a genome-wide study. Neuroreport 18:1761-1764.

Nielsen MS, Madsen P, Christensen EI, Nykjaer A, Gliemann J, Kasper D, Pohlmann R, Petersen CM (2001) The sortilin cytoplasmic tail conveys Golgi-endosome transport and binds the VHS domain of the GGA2 sorting protein. EMBO J 20:2180-2190.

Nyborg AC, Ladd TB, Zwizinski CW, Lah JJ, Golde TE (2006) Sortilin, SorCS1b, and SorLA Vps10p sorting receptors, are novel gammasecretase substrates. Mol Neurodegener 1:3.

Offe K, Dodson SE, Shoemaker JT, Fritz JJ, Gearing M, Levey AI, Lah JJ (2006) The lipoprotein receptor LR11 regulates amyloid beta production and amyloid precursor protein traffic in endosomal compartments. J Neurosci 26:1596-1603.

Peng J, Gygi SP (2001) Proteomics: the move to mixtures. J Mass Spectrom 36:1083-1091.

Peng J, Elias JE, Thoreen CC, Licklider LJ, Gygi SP (2003) Evaluation of multidimensional chromatography coupled with tandem mass spectrometry (LC/LC-MS/MS) for large-scale protein analysis: the yeast proteome. J Proteome Res 2:43-50.

Rogaeva E, Meng Y, Lee JH, Gu Y, Kawarai T, Zou F, Katayama T, Baldwin CT, Cheng R, Hasegawa H, Chen F, Shibata N, Lunetta KL, PardossiPiquard R, Bohm C, Wakutani Y, Cupples LA, Cuenco KT, Green RC, Pinessi L, et al. (2007) The neuronal sortilin-related receptor SORL1 is genetically associated with Alzheimer disease. Nat Genet 39:168-177.

Rohe M, Carlo AS, Breyhan H, Sporbert A, Militz D, Schmidt V, Wozny C, Harmeier A, Erdmann B, Bales KR, Wolf S, Kempermann G, Paul SM, Schmitz D, Bayer TA, Willnow TE, Andersen OM (2008) Sortilinrelated receptor with A-type repeats (SORLA) affects the amyloid precursor protein-dependent stimulation of ERK signaling and adult neurogenesis. J Biol Chem 283:14826-14834.

Sager KL, Wuu J, Leurgans SE, Rees HD, Gearing M, Mufson EJ, Levey AI, Lah
JJ (2007) Neuronal LR11/sorLA expression is reduced in mild cognitive impairment. Ann Neurol 62:640-647.

Scherzer CR, Offe K, Gearing M, Rees HD, Fang G, Heilman CJ, Schaller C, Bujo H, Levey AI, Lah JJ (2004) Loss of apolipoprotein E receptor LR11 in Alzheimer disease. Arch Neurol 61:1200-1205.

Schmidt V, Sporbert A, Rohe M, Reimer T, Rehm A, Andersen OM, Willnow TE (2007) SorLA/LR11 regulates processing of amyloid precursor protein via interaction with adaptors GGA and PACS-1. J Biol Chem 282:32956-32964.

Seshadri S, DeStefano AL, Au R, Massaro JM, Beiser AS, Kelly-Hayes M, Kase CS, D'Agostino RB Sr, Decarli C, Atwood LD, Wolf PA (2007) Genetic correlates of brain aging on MRI and cognitive test measures: a genomewide association and linkage analysis in the Framingham Study. BMC Med Genet 8 Suppl 1:S15.

Spoelgen R, von Arnim CA, Thomas AV, Peltan ID, Koker M, Deng A, Irizarry MC, Andersen OM, Willnow TE, Hyman BT (2006) Interaction of the cytosolic domains of sorLA/LR11 with the amyloid precursor protein (APP) and beta-secretase beta-site APP-cleaving enzyme. J Neurosci $26: 418-428$

Tan EK, Lee J, Chen CP, Teo YY, Zhao Y, Lee WL (2007) SORL1 haplotypes modulate risk of Alzheimer's disease in Chinese. Neurobiol Aging. Advance online publication. Retrieved November 6, 2008. doi:10.1016/j.neurobiolaging.2007.10.013

van Groen T, Kiliaan AJ, Kadish I (2006) Deposition of mouse amyloid beta in human APP/PS1 double and single AD model transgenic mice. Neurobiol Dis 23:653-662.

Webster JA, Myers AJ, Pearson JV, Craig DW, Hu-Lince D, Coon KD, Zismann VL, Beach T, Leung D, Bryden L, Halperin RF, Marlowe L, Kaleem M, Huentelman MJ, Joshipura K, Walker D, Heward CB, Ravid R, Rogers J, Papassotiropoulos A, Hardy J, Reiman EM, Stephan DA (2008) Sorll as an Alzheimer's disease predisposition gene? Neurodegener Dis $5: 60-64$.

Weidemann A, König G, Bunke D, Fischer P, Salbaum JM, Masters CL, Beyreuther K (1989) Identification, biogenesis, and localization of precursors of Alzheimer's disease A4 amyloid protein. Cell 57:115-126.

Yamazaki H, Bujo H, Saito Y (1997) A novel member of the LDL receptor gene family with eleven binding repeats is structurally related to neural adhesion molecules and a yeast vacuolar protein sorting receptor. J Atheroscler Thromb 4:20-26. 